\title{
Gender differences in plaque characteristics of nonculprit lesions in patients with coronary artery disease
}

\author{
Jiangtian Tian ${ }^{1,2}$, Xuedong Wang ${ }^{2}$, Jinwei $\operatorname{Tian}^{2^{*}}$ and Bo $\mathrm{Yu}^{1,2^{*}}$ (D)
}

\begin{abstract}
Background: Although numerous reports suggest sex-related differences in atherosclerosis, limited data describing gender-associated differences in plaque morphology and composition are currently available. The aim of the present study was to compare coronary nonculprit plaque characteristics in women and men with coronary artery disease (CAD) by optical coherence tomography (OCT).

Methods: This was a retrospective study. A total of 187 nonculprit plaques were identified in 103 patients with CAD who underwent OCT imaging of all 3 coronary arteries. These patients included 77 (74.8\%) men and 26 (25.2\%) women.

Results: Female patients were significantly older than males (mean age, $70.8 \pm 7.3$ vs $60.8 \pm 9.8$ years; $P<0.001$ ) and less likely to be current smokers $(P=0.007)$. OCT analysis included the presence of lipid-rich plaque, maximum lipid arc, lipid-core length, lipid index (LI), fibrous cap thickness, and the incidence of thin-cap fibroatheroma (TCFA). Nonculprit plaques in men exhibited greater lipid-core length and LI compared with those of women (9.4 \pm 4.5 vs. $7.3 \pm 4.3 \mathrm{~mm}$, $P=0.024 ; 1615.1 \pm 893.8$ vs. $1237.8 \pm 859.8, P=0.035$, respectively). In the univariate linear regression model, sex and current smoker were all associated with a larger $\mathrm{LI}$, whereas only use of statin was independent risk factor for a larger LI in multivariate analysis.
\end{abstract}

Conclusions: Coronary nonculprit plaques in male patients with CAD contain larger lipid cores than those of female patients.

Keywords: Coronary artery disease, Plaque characteristic, Gender, Optical coherence tomography, Nonculprit plaque

\section{Background}

Coronary artery disease (CAD) is the most common cardiovascular disease caused by coronary stenosis, spasm or occlusion. Despite widespread use of established medical therapies, CAD remains the leading cause of mortality in women in most developed countries. It is estimated that up to 23.6 million people will succumb to cardiovascular disease by 2030 [1] because of increasing obesity, whose rate has doubled between 1980 and 2008, and is expected to further increase.

Epidemiological studies have shown that males are more affected by accelerated atherosclerotic cardiovascular

\footnotetext{
* Correspondence: tianjinweidr2009@163.com; dryu_hum@163.com
2Department of Cardiology, The Second Affiliated Hospital of Harbin Medical

* Correspondence: tianjinweidr2009@163.com; dryu_hum@163.com
2Department of Cardiology, The Second Affiliated Hospital of Harbin Medical University, Harbin 150086, China

${ }^{1}$ Key Laboratory of Myocardial Ischemia, Chinese Ministry of Education, Harbin, China
}

(c) The Author(s). 2019 Open Access This article is distributed under the terms of the Creative Commons Attribution 4.0 International License (http://creativecommons.org/licenses/by/4.0/), which permits unrestricted use, distribution, and reproduction in any medium, provided you give appropriate credit to the original author(s) and the source, provide a link to the Creative Commons license, and indicate if changes were made. The Creative Commons Public Domain Dedication waiver (http://creativecommons.org/publicdomain/zero/1.0/) applies to the data made available in this article, unless otherwise stated.

disease (CVD) compared with women [2-4]. The discovery of sex-dependent disparities in the development of cardiovascular disease has prompted studies aiming at further understanding of ischemic heart disease in women along the continuum of clinical care. In general, the first CVD event occurs 9 years earlier in males compared with females, although this gap narrows with age [5]. The reasons for gender differences in CVD are complex and include clinical risk profile, downstream effects of sex hormones and behavior, although they cannot in many ways fully account for outcome disparity [6-8].

Although women are thought to have a greater symptom burden and a higher rate of functional disability but a lower prevalence of obstructive CAD [9-11], plaque morphology and composition data comparing coronary artery disease in women and men are scarce. A few 
pathological studies suggested that gender may confer differences in coronary plaque characteristics [12]. These findings indicate a potentially distinct form of pathophysiology for atherosclerosis in women. The underlying pathophysiology is probably related to the plaque type. Studies have reported that ruptured and/or vulnerable plaques exist at nonculprit lesions, as well as in culprit segments in acute coronary syndrome (ACS) patients [13-15]. Moreover, patients with ACS that underwent percutaneous coronary intervention were shown to have similar recurrent adverse cardiovascular event rates in culprit and nonculprit lesions (12.9\% versus $11.6 \%$ during a 3-year follow-up period) [16]. However, the characteristics of nonculprit plaques in CAD patients have not been clearly defined. Therefore, to compare coronary nonculprit plaque characteristics in CAD patients in vivo between genders may help understand the underlying pathophysiology of CAD and prevent recurrent cardiovascular events.
Optical coherence tomography (OCT) is an intravascular imaging tool that allows visualization of coronary arteries with high resolution [17]. OCT provides detailed structural information on intracoronary pathology, including plaque morphology, components, and microstructures associated with instability in vivo. The OCT characteristics for various components of atheromatous plaques have been validated in a histology-controlled study [18] As such, the technique provides a unique platform to evaluate the association of gender with coronary artery pathology. The aim of this study was therefore to evaluate differences in OCT-estimated characteristics of nonculprit plaques between women and men with CAD.

\section{Methods}

Study population

Patient selection for the present study is summarized in Fig. 1. A total of 556 patients between January 2013 and

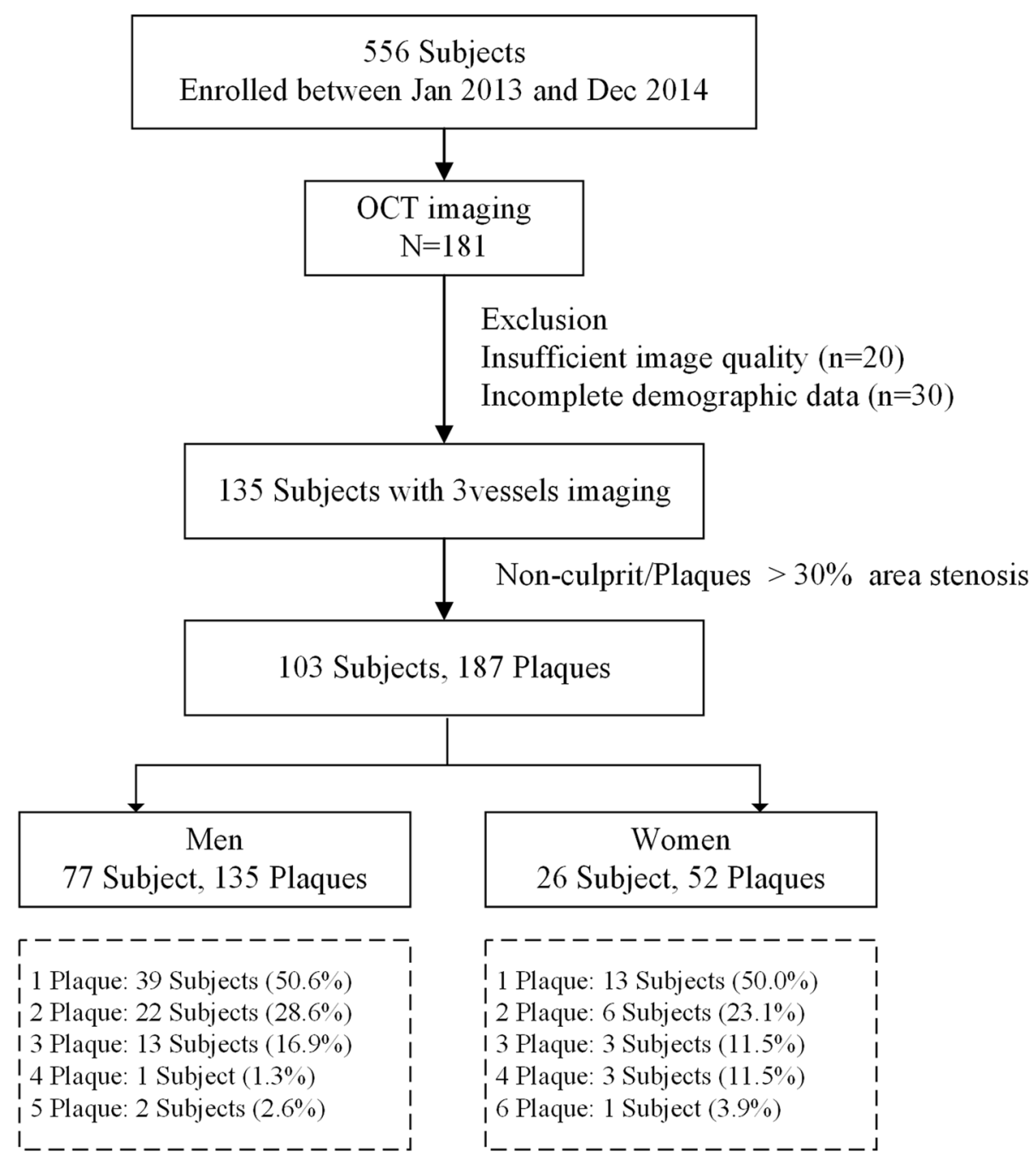

Fig. 1 The patient count breakdown outline 
December 2014 were retrospectively assessed, including 181 who had undergone OCT imaging. Only patients with complete information about clinical history, laboratory data, physical status, and sufficient image quality for all 3 vessels were selected. Therefore, 135 subjects with complete demographic data and sufficient 3-vessel OCT images were included. Plaques were identified with diameter stenosis $>30 \%$ by OCT compared with the reference vessel [19]. Patients without nonculprit plaques were also excluded. Based on angiograms, any plaque treated by percutaneous coronary intervention was excluded. Other exclusion criteria included myocardial infarction, cardiogenic shock, left main coronary artery disease, serious hepatic or renal dysfunction, massive thrombus and poor OCT image quality. Because it would be potentially difficult to acquire and interpret OCT-obtained images, patients with PCI, severe left ventricular dysfunction, or coronary artery bypass grafting were also excluded. Therefore, the final analysis included the remaining 103 subjects, with 187 nonculprit plaques.

This study was approved by the Ethics Review Committee of the Second Affiliated Hospital of Harbin Medical University, Harbin, China. All patients provided written informed consent.

\section{OCT image acquisition}

All patients received standard antiplatelet and antithrombotic therapy with a loading dose of oral aspirin $(300 \mathrm{mg}$ ) and ticagrelor $(180 \mathrm{mg})$. Images were acquired on a commercially available frequency-domain OCT (FD-OCT) (C7XR system, Saint Jude Medical, Westford, MA, US). Intracoronary OCT examination was performed as previously described [20]. Briefly, a 2.7 F OCT imaging catheter (Dragonfly, LightLab Imaging Inc., Westford, MA) was advanced distal to the lesion, and automatic pullback was started as soon as the blood is cleared. All images were de-identified and digitally stored.

\section{Angiographic analysis}

Coronary angiography was performed on a Cardiovascular Angiography Analysis System (CAAS 5.10, Pie Medical Imaging B.V., Maastricht, the Netherlands). The parameters of quantitative coronary angiography (QCA) included lesion length, reference vessel diameter (RVD), minimal lumen diameter (MLD) and diameter stenosis (DS). RVD was defined as the average diameter of the distal and proximal reference diameters. DS was derived as follow: DS $=($ RVD - MLD $) /$ RVD $\times 100 \%$.

\section{OCT image analysis}

Nonculprit plaques with diameter stenosis 20 to $70 \%$ on quantitative coronary angiography and culprit plaques undergoing percutaneous coronary intervention $(\mathrm{PCI})$ were analyzed. A nonculprit plaque was defined as coronary artery stenosis with diameter stenosis 20 to $70 \%$, for which PCI has not been performed. The acquired OCT images were analyzed by two investigators blinded to clinical presentations. In case of discordance between the two investigators, a consensus reading was obtained. Plaque characteristics were defined by previously validated criteria $[21,22]$. A lipid-rich plaque was defined as one with lipid involving $>90^{\circ}$ of the vessel wall circumference (lipid arc) [17]. For lipid-rich plaques, the lipid arc, lipid-core length, thinnest fibrous cap thickness (FCT) were determined, as well as the presence of thin-cap fibroatheroma (TCFA), macrophage accumulation, cholesterol crystals, and microvessels. Lipid-core length was defined as the length of plaque with $>90^{\circ}$ of lipid arc and measured on the longitudinal view. The lipid index, defined as the mean lipid arc multiplied by lipid-core length [20], was also assessed. The fibrous cap thickness (FCT) of each lipid-rich plaque was measured 3 times at its thinnest part, and averaged. A thin cap fibroatheroma (TCFA) was defined as a lipid-rich plaque with a maximum lipid arc $>90^{\circ}$ and a FCT $<65 \mu \mathrm{m}$ [23] (Fig. 2a). A microvessel was defined as a signal-poor void without connection to the lumen, recognized on $\geq 3$ consecutive cross-sectional images [22, 24] (Fig. 2b). Cholesterol crystals were defined as thin, linear regions of high intensity within the plaque [22, 25] (Fig. 2c). Macrophage accumulation on OCT images was identified by increased signal intensity within the plaque, accompanied by heterogeneous backward shadows [26, 27] (Fig. 2d). Calcification was also recorded when an area with low backscatter and a sharp border was identified inside the plaque [22] (Fig. 2e). Plaque disruption was defined as a discontinuity of the fibrous cap with communication between the vessel lumen and the cavity [23] (Fig. 2f). Thrombus was defined as a mass (diameter $\geq 250 \mu \mathrm{m}$ ) attached to the luminal surface or floating within the lumen $[17,22,23]$ (Fig. $2 g$ and h).

\section{Statistical analysis}

All statistical analyses were performed with SPSS version 22.0 (IBM Corp., Armonk, NY). Categorical data were presented as number (percent) and compared by the $X^{2}$ or Fisher exact test, depending on data type. Continuous variables are mean \pm standard deviation (SD); if necessary, median and 25th to 75 th percentile were also presented. Differences between continuous variables were assessed by unpaired Student $\mathrm{t}$ test or Mann-Whitney test. $P<0.05$ was considered statistically significant. For comparisons between groups, analysis was performed by means of the generalized estimating equations approach to take into account the within-subject correlation attributable to multiple plaques analyzed within a single subject. Univariate and multivariate linear regression analyses were performed to assess the relationship between lipid index and other factors. 

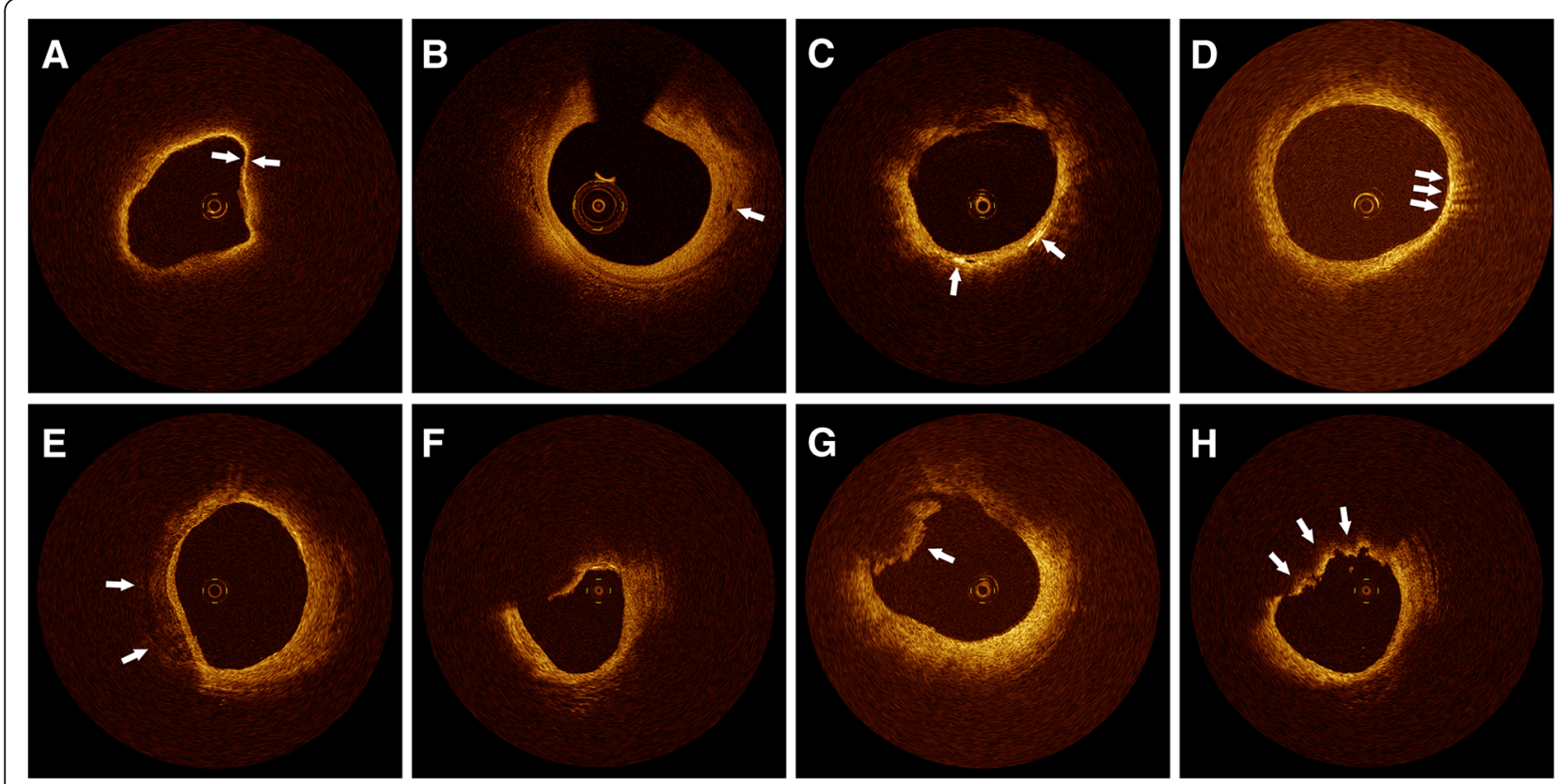

Fig. 2 Representative optical coherence tomography images. a TCFA, defined as a lipid-rich plaque with a fibrous cap thickness $<65 \mu m$ (arrows). b Microvessels are represented by black holes within the plaque (arrow). c Cholesterol crystals are reflected by thin, linear regions of high intensity within the plaque (arrows). d Macrophage accumulation on OCT images, defined as increased signal intensity within the fibrous cap, accompanied by heterogeneous backward shadows (arrows). e Calcification is reflected by an area with low backscatter signal and a sharp border (arrows). f Plaque disruption showing discontinuity of the fibrous cap. $\mathbf{g}$ White (platelet-rich) thrombus is represented by low and homogeneous backscattering with low signal attenuation (arrow). $\mathbf{h}$ Red (red blood cell-rich) thrombus is represented by high backscattering with high attenuation (arrows)

\section{Results}

\section{Patients and angiographic features}

The baseline characteristics of the included patients are listed in Table 1. The 103 patients included 26 (25.2\%) women and $77(74.8 \%)$ men. Female patients were significantly older (mean age, $70.8 \pm 7.3$ vs $60.8 \pm 9.8$ years, respectively; $P<0.001$ ) and had higher levels of low-density lipoprotein cholesterol $(92.2 \pm 27.0$ vs $79.4 \pm$ $27.6 \mathrm{mg} / \mathrm{dL} ; P=0.043)$ compared with men. Male patients were more likely to be current smokers $(29.9 \%$ of men vs $3.8 \%$ of women; $P=0.007$ ). No significant differences were found in the incidence rates of hypertension, diabetes mellitus, and drug use prior to admission between women and men.

Angiographic data are listed in Table 2. Reference vessel diameter (RVD), minimum lumen diameter (MLD) and diameter stenosis (DS) were not significantly different between male and female patients; however, lesion length was greater in men compared with women $(9.4 \pm$ 4.5 vs $7.3 \pm 4.3, P=0.024)$.

\section{OCT findings}

Quantitative and qualitative features of plaque morphologies by OCT are summarized in Table 3. No significant differences were found in minimum lumen area and mean reference vessel area between the two groups.
Lipid-core length $(9.54 \pm 4.5 \mathrm{~mm}$ vs $7.3 \pm 2.7 \mathrm{~mm}, P=$ $0.024)$ and lipid index $\left(1615.1 \pm 893.8 \mathrm{~mm}^{2}\right.$ vs $1237.8 \pm$ $\left.859.8 \mathrm{~mm}^{2}, P=0.035\right)$ were significantly greater in men compared with women. There were no significant differences in FCT (men, 89.2 $\pm 34.9 \mu \mathrm{m}$; women, 93.4 \pm $48.2 \mu \mathrm{m} ; P=0.597$ ) and TCFA prevalence (men, 37.7\%; women, $46.2 \% ; P=0.444)$. The prevalence rates of other microstructures, such as disruption, calcification, microvessels, or cholesterol crystals, were not significantly different between genders.

\section{Univariate and multivariate linear regression models for Liped index}

Table 4 shows the univariate and multivariate linear regression models. In the univariate model, sex and current smoker were all associated with a larger lipid index. Age, use of statin and aspirin were all associated with a smaller lipid index. The multivariate linear regression model demonstrated that only use of statin were an associated factor for a smaller lipid index after adjustment for other factors.

\section{Discussion}

This OCT study focused on patients with CAD, and assessed gender differences in the characteristics of nonculprit plaques. We demonstrated that nonculprit plaques 
Table 1 Baseline clinical characteristics

\begin{tabular}{|c|c|c|c|}
\hline Variable & Men, $n=77$ & Women, $n=26$ & $P$ Value \\
\hline Age, y & $60.8 \pm 9.8$ & $70.8 \pm 7.3$ & $<0.001$ \\
\hline \multicolumn{4}{|l|}{ Risk factors } \\
\hline Hypertension, n (\%) & $47(61.4)$ & $13(50.0)$ & 0.324 \\
\hline Dyslipidemia, n (\%) & $39(50.6)$ & $15(57.7)$ & 0.534 \\
\hline Diabetes mellitus, n (\%) & $31(40.3)$ & $10(38.5)$ & 0.871 \\
\hline Current smoker, n (\%) & $23(29.9)$ & $1(3.8)$ & 0.007 \\
\hline \multicolumn{4}{|c|}{ Medications before admission } \\
\hline Aspirin, n (\%) & $63(81.8)$ & $22(84.6)$ & 0.745 \\
\hline Statins, n (\%) & $57(74.0)$ & $21(80.8)$ & 0.488 \\
\hline$\beta$-Blockers, n (\%) & $29(37.7)$ & $10(38.5)$ & 0.942 \\
\hline ACE inhibitors, n (\%) & $19(24.7)$ & $7(26.9)$ & 0.820 \\
\hline \multicolumn{4}{|l|}{ Biochemistry data } \\
\hline $\mathrm{TC}, \mathrm{mg} / \mathrm{dL}$ & $151.6 \pm 37.5$ & $166.6 \pm 37.5$ & 0.082 \\
\hline $\mathrm{LDL}-\mathrm{C}, \mathrm{mg} / \mathrm{dL}$ & $79.4 \pm 27.6$ & $92.2 \pm 27.0$ & 0.043 \\
\hline $\mathrm{HDL}-\mathrm{C}, \mathrm{mg} / \mathrm{dL}$ & $40.2 \pm 7.6$ & $43.1 \pm 12.6$ & 0.164 \\
\hline $\mathrm{TG}, \mathrm{mg} / \mathrm{dL}$ & $178.4 \pm 167.7$ & $149.9 \pm 65.2$ & 0.402 \\
\hline $\mathrm{HbA}_{1 c,} \%$ & $6.6 \pm 1.3$ & $6.9 \pm 1.5$ & 0.415 \\
\hline hs-CRP, mg/L & $3.0 \pm 2.8$ & $1.6 \pm 1.3$ & 0.082 \\
\hline Creatinine, mg/L & $0.9 \pm 0.2$ & $0.8 \pm 0.2$ & 0.018 \\
\hline Fasting glucose, mg/L & $116.1 \pm 41.8$ & $139.1 \pm 68.0$ & 0.113 \\
\hline
\end{tabular}

Abbreviations: $H b A_{1 C}$ glycated hemoglobin, $H D L-C$ high-density lipoprotein cholesterol, hs-CRP high-sensitivity C-reactive protein, IQR interquartile range, LDL-C low-density lipoprotein cholesterol, TC total cholesterol, TG triglycerides. Data are $\mathrm{n}(\%)$ or mean $\pm \mathrm{SD}$

had reduced lipid index in female patients with CAD compared with male patients. The univariate linear regression model demonstrated that sex and current smoker were all associated with a larger LI, whereas in multivariate model only use of statin was independent risk factor for a larger LI.

Table 2 Angiographic findings

\begin{tabular}{|c|c|c|c|}
\hline Variable & Men, $n=135$ & Women, $n=52$ & $P$ Value \\
\hline Plaque location, n (\%) & & & 0.739 \\
\hline$L A D, n(\%)$ & $45(33.3)$ & $15(28.8)$ & \\
\hline LCX, n (\%) & $37(27.4)$ & $17(32.7)$ & \\
\hline $\mathrm{RCA}, \mathrm{n}(\%)$ & $53(39.3)$ & $20(38.5)$ & \\
\hline Multivessel disease, n (\%) & $38(49.4)$ & $13(50.0)$ & 0.954 \\
\hline \multicolumn{4}{|l|}{ QCA findings } \\
\hline lesion length, mm & $9.4 \pm 4.5$ & $7.3 \pm 4.3$ & 0.024 \\
\hline $\mathrm{RVD}, \mathrm{mm}$ & $3.0 \pm 0.5$ & $3.0 \pm 0.6$ & 0.640 \\
\hline MLD, mm & $1.9 \pm 0.4$ & $1.9 \pm 0.4$ & 0.645 \\
\hline Diameter stenosis, \% & $37.3 \pm 7.6$ & $36.9 \pm 7.7$ & 0.750 \\
\hline
\end{tabular}

Abbreviations: $L A D$ left anterior descending artery, $L C X$ left circumflex artery, $R C A$ right coronary artery; $Q C A, M L D$ minimum lumen diameter, $R V D$ reference vessel diameter, Data are $\mathrm{n}(\%)$ or mean $\pm \mathrm{SD}$
Table 3 Optical coherence tomography (OCT) findings

\begin{tabular}{llll}
\hline Variables & Men, $n=77$ & Women, $n=26$ & $P$ Value \\
\hline MLA, mm ${ }^{2}$ & $3.1 \pm 1.3$ & $3.1 \pm 1.3$ & 0.746 \\
Mean RVA, mm ${ }^{2}$ & $7.1 \pm 2.5$ & $7.3 \pm 2.7$ & 0.684 \\
Stenosis area, \% & $42.6 \pm 11.0$ & $42.9 \pm 10.8$ & 0.880 \\
Lipid-rich plaque & & & \\
$\quad$ Lipid-rich, n (\%) & $87(64.4)$ & $35(67.3)$ & 0.713 \\
$\quad$ Maximum lipid arc & $224.1 \pm 63.6$ & $210.0 \pm 58.5$ & 0.259 \\
$\quad$ Lipid length, mm & $9.4 \pm 4.5$ & $7.3 \pm 4.3$ & 0.024 \\
$\quad$ Lipid index & $1615.1 \pm 893.8$ & $1237.8 \pm 859.8$ & 0.035 \\
$\quad$ FCT, $\mu m$ & $89.2 \pm 34.9$ & $93.4 \pm 48.2$ & 0.597 \\
$\quad$ TCFA, $\mathrm{n}(\%)$ & $29(37.7)$ & $12(46.2)$ & 0.444 \\
Disruption, $\mathrm{n}(\%)$ & $4(3.0)$ & $5(9.6)$ & 0.057 \\
Calcification, $\mathrm{n}(\%)$ & $42(31.1)$ & $15(28.8)$ & 0.763 \\
Macrophage, $\mathrm{n}(\%)$ & $42(31.1)$ & $17(32.7)$ & 0.835 \\
Microvessels (MC), n (\%) & $50(37.0)$ & $27(51.9)$ & 0.064 \\
Cholesterol crystal, n (\%) & $12(8.9)$ & $5(9.6)$ & 0.670 \\
Thrombus, n (\%) & $2(1.5)$ & $3(5.7)$ & 0.103 \\
\hline Abbrevatons: & &
\end{tabular}

Abbreviations: $F C T$ fibrous cap thickness, IQR interquartile range, MLA minimum lumen area, RVA reference vessel area, SD standard deviation, TCFA thin-cap fibroatheroma. Data are $\mathrm{n}(\%)$ or mean $\pm \mathrm{SD}$

At the time of presentation with CAD, women tend to be 10 years older than men [28]. Consistent with previously reported data, the present study found that women were significantly older when presenting with suspected CAD than men, with average ages of 70.8 and 60.8 years in women and men, respectively. It has been reported that the burden of coronary plaque increases with age

Table 4 Univariate and Multivariate Linear Regression Models for Lipid Index

\begin{tabular}{|c|c|c|c|c|}
\hline & \multicolumn{2}{|c|}{ Univariate Model } & \multicolumn{2}{|c|}{ Multivariate Model } \\
\hline & $\beta$ Coefficient & $P$ Value & $\beta$ Coefficient & $P$ Value \\
\hline$\overline{\text { Age }}$ & -21.012 & 0.004 & -2.879 & 0.772 \\
\hline Sex & 375.867 & 0.037 & 266.559 & 0.259 \\
\hline Hypertension & 83.188 & 0.626 & 158.827 & 0.397 \\
\hline Dyslipidemia & 221.820 & 0.458 & 552.927 & 0.097 \\
\hline Current smoker & 469.748 & 0.014 & 163.004 & 0.474 \\
\hline Diabetes mellitus & 304.668 & 0.070 & 230.157 & 0.171 \\
\hline Statins & -644.889 & 0.000 & -783.199 & 0.023 \\
\hline$\beta$-Blockers & -226.489 & 0.171 & 9.594 & 0.961 \\
\hline Aspirin & -510.237 & 0.014 & 307.245 & 0.447 \\
\hline TC & -0.383 & 0.855 & -0.688 & 0.889 \\
\hline LDL-C & 3.453 & 0.200 & 1.754 & 0.769 \\
\hline HDL-C & -0.103 & 0.991 & 4.501 & 0.659 \\
\hline $\mathrm{TG}$ & -0.743 & 0.142 & -0.617 & 0.486 \\
\hline
\end{tabular}

Abbreviations: $H D L-C$ high-density lipoprotein cholesterol, LDL-C low-density lipoprotein cholesterol, $T C$ total cholesterol, $T G$ triglycerides. $P$ values are from the inference using the generalized estimating equation-based sandwich SE estimates 
[29], consistent with this result, univariate regression analysis in this study showed that age was positively correlated with LI. Even so, in present study, the LI of nonculprit plaques in man was still greater than that of plaque in female. In the present study, the active smoking rate of different gender patients was also different. The rate of current smokers in male patients was significantly higher than that of female patients. Previous angiographic and OCT studies shown that active smoking could increasing lipid accumulation [30, 31]. Our univariate regression analysis also showed that smoking was associated with greater LI, however, multivariate regression analysis showed that neither smoking nor gender was independent factor for LI. Therefore, smoking might contribute in part to the difference in nonculprit plaques between different genders.

Pathological studies have previously revealed differences in plaque morphologies between men and women [32-34]. A previous report demonstrated that among patients with ACS, women have less extensive coronary artery disease, by both angiographic and intravascular ultrasound (IVUS) measures, with lesions in women having less plaque rupture, reduced necrotic core and calcium, similar plaque burden, and smaller lumens compared with male patients, despite having more comorbid risk factors [35]. In this study, the LDL levels in female patients were significantly higher than those in male patients, however, the LI of female patients was smaller. Monique et al. [36] also used IVUS and near-infrared spectroscopy (NIRS) in CAD patients, and demonstrated that women have more favorable plaque characteristics than man, despite their worse risk profile.

On the other hand, several imaging studies have reported undifferentiated data regarding the relationship between gender and plaque characteristics. In patients with stable CAD, a multimodality intravascular imaging study observed no sex-specific differences in plaque morphology, as measured by lipid content, thin-cap fibroatheroma, calcification, microvessels, and macrophages in men and women [37]. Additionally, in patients with ACS, a previous study found no gender differences in the number of plaques with disruption, calcification, or thrombus [38]. Similarly, our team recently found that in patients with a first ST-segment elevation myocardial infarction (STEM), there are no differences in culprit plaque features between women and men [39]. In this study, nonculprit lesions in women with suspected CAD exhibited shorter lipid-cores and smaller LI compared with male counterparts. However, this did not translate into differences in fibrous cap thickness and TCFA frequency between genders. Whether this reflects differential effects of risk factor exposure on the artery wall in women requires further investigation. Gender-related differences were not observed in cholesterol crystals and calcification within nonculprit plaques in this study. The current findings are consistent with those of previous OCT studies [40] and complete previous reports assessing plaque features by OCT in CAD patients $[39,41]$.

The total number of deaths from cardiovascular diseases (CVD) is greater in women compared with men $[28,42]$. However, OCT Imaging studies showed that plaque morphology in female CAD patients is not different from that of men, or even more stable compared with male plaques $[39,41,42]$. The reasons for gender-related differences in clinical outcomes remain unclear. A possible reason for higher mortality and morbidity in women might be the higher burden of risk factors compared with men, including higher prevalence rates of risk factors not included in traditional risk-estimation algorithms, such as depression, physical inactivity, and a family history of premature CAD [43]. Indeed, women are more affected by anxiety and depression than men [28], which may explain worse recovery in women, to a certain extent. Notably, the Women's Ischemia Syndrome Evaluation study highlighted the importance of non-obstructive coronary artery disease, such as ischemia caused by microvascular disease, which is more commonly found in women compared with men $[2,44]$. This phenomenon may partly explain why women have more favorable plaque characteristics, including reduced IL in nonculprit lesions, but show worse clinical outcomes. Long-term follow-up studies are required to comprehensively evaluate the clinical consequences of these differences.

\section{Study limitations}

The limitations of the present study should be noted. First, this was a retrospective observational study from a database; therefore, selection bias may have influenced the above results. Secondly, adjustment for potential confounding factors was not performed because of the limited sample size. Thirdly, the study design had an intrinsic limitation related to the imbalance between women and men in the general population. Nonetheless, this imbalance reflects the true distribution of patients with CAD.

\section{Conclusions}

In summary, nonculprit plaques contain reduced lipid cores in female patients with CAD compared with male counterparts. These findings highlight distinct pathophysiological features for atherosclerosis between genders, potentially leading to clinical presentation differences.

\footnotetext{
Abbreviations

ACS: Acute coronary syndrome; CAAS: Cardiovascular Angiography Analysis System; CAD: Coronary artery disease; CVD: Cardiovascular disease; DS: Diameter stenosis; FCT: Fibrous cap thickness; IVUS: Intravascular ultrasound; LI: Lipid index; MLD: Minimal lumen diameter; OCT: Optical coherence tomography; PCl: Percutaneous coronary intervention: QCA: Quantitative coronary angiography; RVD: Reference vessel diameter; SD: Standard deviation; STEM: ST-segment elevation myocardial infarction; TCFA: Thin-cap fibroatheroma
} 


\section{Acknowledgements}

The authors would like to thank all the investigators and support staff involved in the completion of this study.

\section{Funding}

This study is supported by grants from Natural Science Foundation of China (Tian J, 91739113), Natural Science Foundation of China (Tian J, 81571749) and Key Program of National Natural Science Foundation of China (Yu B, 81330033)

\section{Availability of data and materials}

The datasets used and/or analysed during the current study are available from the corresponding author on reasonable request.

\section{Authors' contributions}

JTT and XDW carried out the studies, participated in collecting data, and drafted the manuscript. BY and JWT performed the research design and data analysis, helped to draft the manuscript. All authors read and approved the final manuscript.

\section{Ethics approval and consent to participate}

This study was approved by the Ethics Review Committee of the Second Affiliated Hospital of Harbin Medical University, Harbin, China. All patients provided written informed consent.

\section{Consent for publication}

Not applicable.

\section{Competing interests}

The authors declare that they have no competing interests.

\section{Publisher's Note}

Springer Nature remains neutral with regard to jurisdictional claims in published maps and institutional affiliations.

Received: 1 November 2018 Accepted: 15 February 2019 Published online: 26 February 2019

\section{References}

1. Laslett LJ, Alagona P Jr, Clark BA 3rd, Drozda JP Jr, Saldivar F, Wilson SR, et al. The worldwide environment of cardiovascular disease: prevalence, diagnosis, therapy, and policy issues: a report from the American College of Cardiology. J Am Coll Cardiol. 2012;60:S1-49.

2. Bairey Merz N, Bonow RO, Sopko G, Balaban RS, Cannon RO 3rd, Gordon D, et al. Women's ischemic syndrome evaluation: current status and future research directions: report of the National Heart, lung and blood institute workshop: October 2-4, 2002: executive summary. Circulation. 2004;109: 805-7.

3. Mozaffarian D, Benjamin EJ, Go AS, Arnett DK, Blaha MJ, Cushman M, et al. Heart disease and stroke statistics--2015 update: a report from the American Heart Association. Circulation. 2015;131:e29-322.

4. Shaw LJ, Bairey Merz CN, Pepine CJ, Reis SE, Bittner V, Kelsey SF, et al. Insights from the NHLBI-sponsored Women's ischemia syndrome evaluation (WISE) study: part I: gender differences in traditional and novel risk factors, symptom evaluation, and gender-optimized diagnostic strategies. J Am Coll Cardiol. 2006;47:S4-s20.

5. Anand SS, Islam S, Rosengren A, Franzosi MG, Steyn K, Yusufali AH, et al. Risk factors for myocardial infarction in women and men: insights from the INTERHEART study. Eur Heart J. 2008;29:932-40.

6. Mendelsohn ME, Karas RH. Molecular and cellular basis of cardiovascular gender differences. Science. 2005;308:1583-7.

7. Caboral MF. Update on cardiovascular disease prevention in women. Am J Nurs. 2013;113:26-33 quiz, 44.

8. Bavry AA, Limacher MC. Prevention of cardiovascular disease in women. Semin Reprod Med. 2014;32:447-53

9. Eitel I, Desch S, de Waha S, Fuernau G, Gutberlet M, Schuler G, et al. Sex differences in myocardial salvage and clinical outcome in patients with acute reperfused ST-elevation myocardial infarction: advances in cardiovascular imaging. Circ Cardiovasc Imaging. 2012;5:119-26.
10. Vaccarino V, Parsons L, Every NR, Barron HV, Krumholz HM. Sex-based differences in early mortality after myocardial infarction. National Registry of myocardial infarction 2 participants. N Engl J Med. 1999;341:217-25.

11. Ostadal B, Ostadal P. Sex-based differences in cardiac ischaemic injury and protection: therapeutic implications. Br J Pharmacol. 2014;171:541-54.

12. Bentzon JF, Otsuka F, Virmani R, Falk E. Mechanisms of plaque formation and rupture. Circ Res. 2014;114:1852-66.

13. Asakura M, Ueda Y, Yamaguchi O, Adachi T, Hirayama A, Hori M, et al. Extensive development of vulnerable plaques as a pan-coronary process in patients with myocardial infarction: an angioscopic study. J Am Coll Cardiol. 2001;37:1284-8

14. Rioufol G, Finet G, Ginon I, Andre-Fouet X, Rossi R, Vialle E, et al. Multiple atherosclerotic plaque rupture in acute coronary syndrome: a three-vessel intravascular ultrasound study. Circulation. 2002;106:804-8.

15. Kotani J, Mintz GS, Castagna MT, Pinnow E, Berzingi CO, Bui AB, et al. Intravascular ultrasound analysis of infarct-related and non-infarct-related arteries in patients who presented with an acute myocardial infarction. Circulation. 2003;107:2889-93.

16. Stone GW, Maehara A, Lansky AJ, de Bruyne B, Cristea E, Mintz GS, et al. A prospective natural-history study of coronary atherosclerosis. N Engl J Med. 2011;364:226-35.

17. Jang IK, Tearney GJ, MacNeill B, Takano M, Moselewski F, Iftima N, et al. In vivo characterization of coronary atherosclerotic plaque by use of optical coherence tomography. Circulation. 2005;111:1551-5.

18. Yabushita H, Bouma BE, Houser SL, Aretz HT, Jang IK, Schlendorf KH, et al. Characterization of human atherosclerosis by optical coherence tomography. Circulation. 2002:106:1640-5.

19. Kato K, Yonetsu T, Jia H, Abtahian F, Vergallo R, Hu S, et al. Nonculprit coronary plaque characteristics of chronic kidney disease. Circ Cardiovasc Imaging. 2013;6:448-56

20. Kato K, Yonetsu T, Kim SJ, Xing L, Lee H, McNulty I, et al. Nonculprit plaques in patients with acute coronary syndromes have more vulnerable features compared with those with non-acute coronary syndromes: a 3-vessel optical coherence tomography study. Circ Cardiovasc Imaging. 2012;5:433-40.

21. Virmani R, Burke AP, Farb A, Kolodgie FD. Pathology of the vulnerable plaque. J Am Coll Cardiol. 2006;47:C13-C8.

22. Tearney GJ, Regar E, Akasaka T, Adriaenssens T, Barlis P, Bezerra HG, et al. Consensus standards for acquisition, measurement, and reporting of intravascular optical coherence tomography studies: a report from the international working Group for Intravascular Optical Coherence Tomography Standardization and Validation. J Am Coll Cardiol. 2012;59:1058-72.

23. Prati F, Regar E, Mintz GS, Arbustini E, Di Mario C, Jang IK, et al. Expert review document on methodology, terminology, and clinical applications of optical coherence tomography: physical principles, methodology of image acquisition, and clinical application for assessment of coronary arteries and atherosclerosis. Eur Heart J. 2010;31:401-15.

24. Kitabata H, Tanaka A, Kubo T, Takarada S, Kashiwagi M, Tsujioka H, et al. Relation of microchannel structure identified by optical coherence tomography to plaque vulnerability in patients with coronary artery disease. Am J Cardiol. 2010;105:1673-8.

25. Kataoka Y, Puri R, Hammadah M, Duggal B, Uno K, Kapadia SR, et al Cholesterol crystals associate with coronary plaque vulnerability in vivo. J Am Coll Cardiol. 2015:65:630-2.

26. Tearney GJ, Yabushita H, Houser SL, Aretz HT, Jang IK, Schlendorf KH, et al. Quantification of macrophage content in atherosclerotic plaques by optical coherence tomography. Circulation. 2003;107:113-9.

27. MacNeill BD, Jang IK, Bouma BE, Iftimia N, Takano M, Yabushita $H$, et al. Focal and multi-focal plaque macrophage distributions in patients with acute and stable presentations of coronary artery disease. J Am Coll Cardiol. 2004:44:972-9.

28. Ladwig KH, Waller C. Gender-specific aspects of coronary heart disease. Bundesgesundheitsblatt Gesundheitsforschung Gesundheitsschutz. 2014;57: 1083-91.

29. Tota-Maharaj R, Blaha MJ, Rivera JJ, Henry TS, Choi EK, Chang SA, et al. Differences in coronary plaque composition with aging measured by coronary computed tomography angiography. Int J Cardiol. 2012;158:240-5.

30. Rioufol G, Zeller M, Dentan G, Laurent Y, L'Huillier D, Phillips HR, et al. Predictors and prognosis for complex coronary lesions in patients with acute myocardial infarction: data from RICO survey. Am Heart J. 2007;154:330-5.

31. Abtahian F, Yonetsu T, Kato K, Jia H, Vergallo R, Tian J, et al. Comparison by optical coherence tomography of the frequency of lipid coronary plaques 
in current smokers, former smokers, and nonsmokers. Am J Cardiol. 2014; 114:674-80.

32. Mautner SL, Lin F, Mautner GC, Roberts WC. Comparison in women versus men of composition of atherosclerotic plaques in native coronary arteries and in saphenous veins used as aortocoronary conduits. J Am Coll Cardiol. 1993;21:1312-8

33. Yahagi K, Davis HR, Arbustini E, Virmani R. Sex differences in coronary artery disease: pathological observations. Atherosclerosis. 2015;239:260-7.

34. Farb A, Burke AP, Tang AL, Liang TY, Mannan P, Smialek J, et al. Coronary plaque erosion without rupture into a lipid core. A frequent cause of coronary thrombosis in sudden coronary death. Circulation. 1996;93:1354-63.

35. Lansky AJ, Ng VG, Maehara A, Weisz G, Lerman A, Mintz GS, et al. Gender and the extent of coronary atherosclerosis, plaque composition, and clinical outcomes in acute coronary syndromes. JACC Cardiovasc Imaging. 2012;5: S62-72.

36. Ten Haaf ME, Rijndertse M, Cheng JM, de Boer SP, Garcia-Garcia HM, van Geuns RM, et al. Sex differences in plaque characteristics by intravascular imaging in patients with coronary artery disease. Eurolntervention. 2017;13: $320-8$.

37. Bharadwaj AS, Vengrenyuk Y, Yoshimura T, Baber U, Hasan C, Narula J, et al. Multimodality intravascular imaging to evaluate sex differences in plaque morphology in stable CAD. JACC Cardiovasc Imaging. 2016;9:400-7.

38. Chia S, Christopher Raffel O, Takano M, Tearney GJ, Bouma BE, Jang IK. Invivo comparison of coronary plaque characteristics using optical coherence tomography in women vs. men with acute coronary syndrome. Coron Artery Dis. 2007;18:423-7.

39. Sun R, Sun L, Fu Y, Liu H, Xu M, Ren X, et al. Culprit plaque characteristics in women vs men with a first ST-segment elevation myocardial infarction: in vivo optical coherence tomography insights. Clin Cardiol. 2017:40:1285-90.

40. Pena JM, Min JK. Coronary artery disease: sex-related differences in CAD and plaque characteristics. Nat Rev Cardiol. 2016;13:318-9.

41. Kataoka Y, Puri R, Hammadah M, Duggal B, Uno K, Kapadia SR, et al. Sex differences in nonculprit coronary plaque microstructures on frequencydomain optical coherence tomography in acute coronary syndromes and stable coronary artery disease. Circ Cardiovasc Imaging. 2016;9.

42. Lawton JS. Sex and gender differences in coronary artery disease. Semin Thorac Cardiovasc Surg. 2011;23:126-30

43. Hemal K, Pagidipati NJ, Coles A, Dolor RJ, Mark DB, Pellikka PA, et al. Sex differences in demographics, risk factors, presentation, and noninvasive testing in stable outpatients with suspected coronary artery disease: insights from the PROMISE trial. JACC Cardiovasc Imaging. 2016;9:337-46.

44. Vaccarino V. Ischemic heart disease in women: many questions, few facts. Circ Cardiovasc Qual Outcomes. 2010;3:111-5.

Ready to submit your research? Choose BMC and benefit from:

- fast, convenient online submission

- thorough peer review by experienced researchers in your field

- rapid publication on acceptance

- support for research data, including large and complex data types

- gold Open Access which fosters wider collaboration and increased citations

- maximum visibility for your research: over $100 \mathrm{M}$ website views per year

At $\mathrm{BMC}$, research is always in progress.

Learn more biomedcentral.com/submissions 